\title{
Combining ground penetrating radar and seismic surveys in the assessment of cultural heritage buildings: The study of roofs, columns, and ground of the gothic church Santa Maria del Mar, in Barcelona (Spain)
}

\author{
Vega Perez-Gracia ${ }^{1}$ (D) | Sonia Santos-Assunçao ${ }^{3}$ | Oriol Caselles ${ }^{2} \mid$ Jaime Clapes $^{2}$ | \\ Viviana Sossa ${ }^{1}$
}

${ }^{1}$ Department of Strength of Materials and Structural Engineering (RMEE), Polytechnic University of Catalonia (BarcelonaTech), Barcelona, Spain

${ }^{2}$ Department of Civil and Environmental Engineering (ECA), Polytechnic University of Catalonia (BarcelonaTech), Barcelona, Spain

${ }^{3}$ Department of Fluid Mechanics, Polytechnic University of Catalonia (BarcelonaTech), Barcelona, Spain

\section{Correspondence}

Vega Perez-Gracia, Department of Strength of Materials and Structural Engineering (RMEE), Polytechnic University of Catalonia (BarcelonaTech), Barcelona, Spain.

Email: vega.perez@upc.edu

Funding information

Spanish Ministry of Economy and Competitiveness (MINECO) of the Spanish Government and European Regional Development Fund (FEDER) of the European Union (UE), Grant/Award Numbers: CGL2011-23621 and CGL2015-65913-P;

European Commission, Grant/Award Number: 244123

\begin{abstract}
Summary
Combined non-destructive techniques are applied in the study of a historical building in Barcelona. Santa Maria del Mar is a magnificent Mediterranean gothic church built between 1329 and 1383. Two of the most important characteristics of this building are the slender columns and the almost flat rooftop. This structure, used to create a visual impression of a unique space, transmits high loads to the tall columns. Previous to restoration, vaults, roofs, and columns were extensively assessed with non-destructive tests, in order to improve the knowledge of those structures. This information will be used in further simulations to analyse load distributions at each part of the structure. Ground and floor were also studied. The analysis of the columns was based on groundpenetrating radar (GPR) surveys and on seismic tomography. Finally, the dynamic behaviour of the structure was determined by seismic monitoring of the main nave and the bell tower. Results obtained at the radar survey highlight the existence of unexpected anomalies in homogeneous materials, supporting the hypothesis of an inner structure between arches and roof composed by hollow elements. Seismic tomography defined the inner geometry of the columns and detected some damage or lower quality stone in various zones. Seismic monitoring established the perfect junction between the bell tower and the main nave. GPR survey on the floor allowed detecting a large number of graves, and some images suggest the existence of large underground walls and some of the foundations of the main façade.
\end{abstract}

\section{KEYWORDS}

building assessment, cultural heritage, ground-penetrating radar, masonry, seismic monitoring, seismic tomography 


\section{1 | INTRODUCTION}

Cultural heritage preservation requires a wide knowledge of the built structures in order to define the appropriate action to protect them. The knowledge of the history (the construction and further changes) is needed to understand the present state of the protected heritage. ${ }^{1}$ However, in many cases, part of the changes on the structure, or details about its construction, is unknown. In those cases, as well as in the case of possible damage in the structure, a multidisciplinary combination of inspection techniques is recommended to improve the general comprehension about the processes and behaviour of the structures and to provide a wide diagnostic of damage. Therefore, an important task for preservation is to fulfil the most detailed study as possible of the structural characteristics and its current state of conservation. The special characteristics of cultural heritage usually require a non-destructive assessment, being the destructive tests limited to few areas when possible. However, in some cases, the structure of the monument makes difficult the access and the application of those non-destructive techniques. Combining methodologies is, in those studies of complex structures, the only solution to obtain enough data to preserve the building. Examples of those complex structures are gothic churches and cathedrals. ${ }^{2}$ The importance of such buildings in European cities is remarkable because they are the most relevant cultural heritage buildings and represent the middle age period of those communities.

In this paper, the multidisciplinary assessment of the basilica of Santa Maria del Mar, combining groundpenetrating radar (GPR) surveys, seismic tomography, and seismic monitoring, is presented. The three techniques have been applied to characterize the structure and to assess the state of conservation of roofs, columns, and ground floors.

The basilica of Santa Maria del Mar was erected in the neighbourhood La Ribera supported by the parishioners of the district with their own work or with capital, close to the land reclaimed to the sea. ${ }^{3}$ During the XII to XV centuries, the district was an important commercial area, and many merchants, important artisans, and minor nobles built their residences. The works in the actual church began in 1329 and finished in 1383, under the direction of Berenguer de Montagut and helped by Ramon Despuig. Some authors point out the existence of an older pre-Romanesque chapel under the actual cathedral or even though the remains of the Roman amphitheatre of Barcelona. ${ }^{4}$ The church suffered serious damage after the construction: In 1397, a fire destroyed the first four vaults, and several years later, in 1428, an important earthquake at about $100-\mathrm{km}$ distance to the epicentre crash the rose window killing several citizens. More recently, on 1936, another fire most likely damaged some columns and vaults.

The church has three naves, being the lateral naves almost as tall as the central nave. The structure is stable, and the weight is supported by octagonal columns, walls, and buttresses. Nowadays, the actual basilica of Santa Maria del Mar church epitomizes the most characteristics of Mediterranean gothic buildings with its slender octagonal columns $(0.6 \mathrm{~m}$ each side, circumscribed $1.45 \mathrm{~m}$ diameter) and its larger distance between columns ( $15 \mathrm{~m})$. The ratio of the main nave height to lateral nave is high (about 0.9), the coverts are flats, and the buttresses are wide. The result is a diaphanous single space (Figure 1). This characteristic differs from the most part of the European gothic structures in which

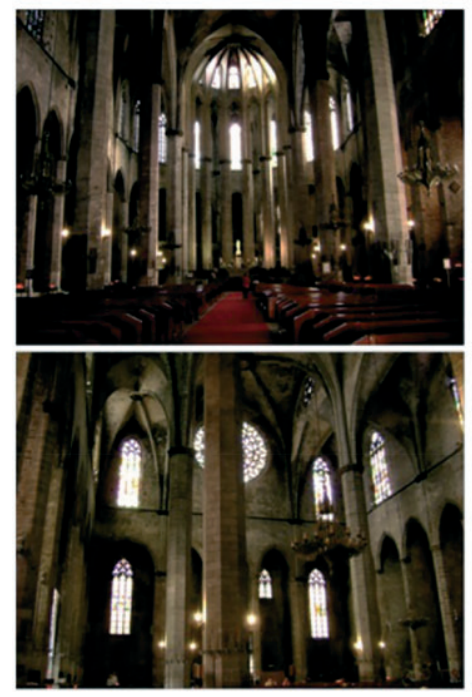

(a)

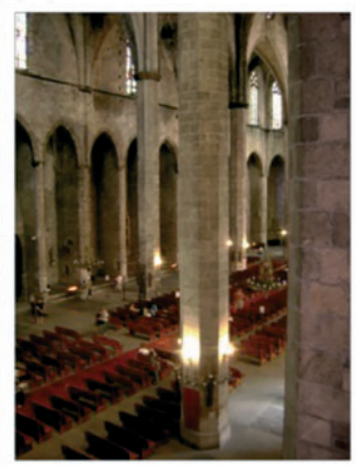

(b)
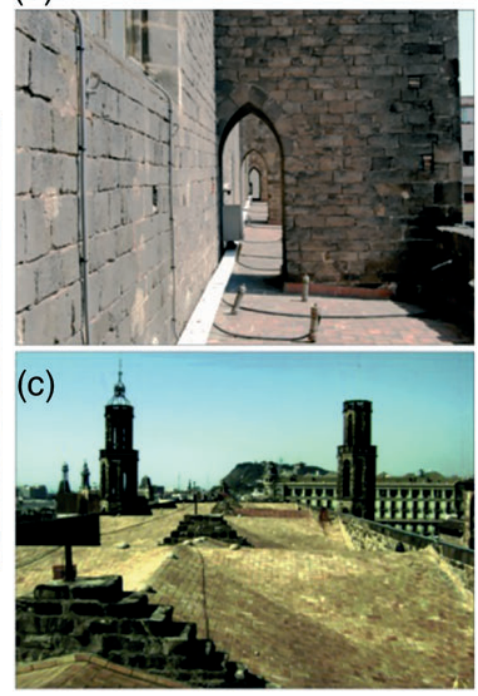

FIGURE 1 Images of the different areas in Santa Maria del Mar basilica. (a) Interior of the church and the slender columns. (b) Roof of the lateral naves and chapels and buttresses. (c) Roof of the main nave 
columns divide the church in three spaces, ${ }^{5}$ being the lateral naves half width of the main nave and the same height width of the church.

The structure of the church is characterized by the slenderness of the columns, and the lack of fly arches force strategies to lighten the main roofs. One of the strategies was to reduce the weight of the roof by using a mix of pottery and mortar to build the structures between and above the arches. ${ }^{6}$ The construction with voids results into a lighter and more resistant structure.

The restoration of the basilica includes a previous research that obtains information about the constructive techniques, materials, and potential damages. Otherwise, the result could not be accurate enough to preserve the historical building and to permit its actual use. In addition, the broad knowledge of the structure could help in the comprehension of the ancient constructive techniques, allowing a deeper understanding of the past societies. The first visual inspection determined the existence of damage, allowing a first characterization of the structural element based on their external shape, materials, and position. As part of further non-destructive studies, the evaluation was focused on some specific structural elements, using combined techniques. The assessment consisted on determining the internal constructive structure and finding the solutions to reduce the weight of the roof and upper elements, besides the structural behaviour of the building. GPR, seismic tomography, and seismic monitoring were used preceding more invasive explorations. Non-destructive testing is usually recommended as previous analysis in the assessment of structures after the visual inspection may be applied to different methodologies to masonry structures. ${ }^{7}$ Combination of GPR and seismic survey techniques or ultrasonic testing in cultural heritage assessment was successfully utilized to select the zones or the structural elements where further studies might be required. Both techniques were effectively managed to detect damage in possible damaged areas. ${ }^{8-11}$ They were also successfully combined to study the arrangement of materials in constructive elements ${ }^{11-14}$ and in the detection of wet zones. ${ }^{15-17}$ The application of GPR to masonry structures is nowadays extensively used due to good results in detecting hidden structures, ${ }^{18-20}$ but some ambiguities recommend the use of combined techniques.

Restoration also involved the simulation of the building behaviour. Therefore, a wide knowledge about the structure of the columns and their state of conservation was needed in order to define the most appropriate models to compute an accurate structural analysis of the building. This analysis also might be compared with the measured structural behaviour, defining by the seismic monitoring.

\section{2 | NON-DESTRUCTIVE SURVEYS}

\section{1 | GPR survey}

A commercial SIR-3000 GPR GSSI system was used with three different nominal centre frequency antennas: 200, 400, and $900 \mathrm{MHz}$. The assessment was focused on the ground floor, the roof, and the columns. The position of the 200- and $400-\mathrm{MHz}$ centre frequency antennas along each radar line was determined by means of a survey wheel. The $900-\mathrm{MHz}$ antenna was used in the study of the columns, and the position on each column was determined introducing every 5-cm marks.

In the assessment of the roof, the objective was to determine the thickness of the different structures, detecting the existence of voids and, if possible, defining their distribution. This information was crucial to define the weight supported by the slender columns of the church. Most of the profiles in that area were prospected with the 400-MHz centre frequency antenna (Profiles 4 to 10 in Figure 2) except Profile 3 (around the cylindrical structure result of the union of the ambulatory arches), which was studied using a 900-MHz centre frequency antenna (see Figure 2). All the radar lines were designed regarding the geometry of the elements and the slope and change the level of the surfaces, covering the perimeter, the cylindrical structure over the altar, and the vault of the lateral naves and chapels (Figure 2).

In the study of five columns on the main nave and four columns on the ambulatory (see Figure $2 \mathrm{~d}$ ), a $900-\mathrm{MHz}$ antenna was used to explore them until $1.7 \mathrm{~m}$ high. The main objective was to detect important inner cracks and to determine their internal structural arrangement. The visual inspection indicated higher damage in the base of the columns, so the study was focused on this zone.

Finally, two GPR profiles were carried out to assess the floor in the front wall area, one inside and the other outside the church (Figure 2f). The objectives of these radargrams were to determine the shallow geology and to find buried objects. 
Data processing consisted on a previous zero correction and background removal. After that, an energy decay gain with a scale of 0.2 was applied in order to improve the images and a bandpass filter with cut-off frequencies of 400 and 2,550 $\mathrm{MHz}$ and plateau frequencies of 450 and 2,500 MHz.

Energy decay provides a gain that consists of the division of each one of the points of the trace by an average decay curve determined automatically obtained from all the traces of the radargram. The scale factor is a value that multiplies all the points of the trace after the application of the gain curve. In many cases this factor of scale must be less than 1 to avoid amplitudes higher than the maximum amplitude of the raw profile.

\subsection{Seismic tomography and monitoring}

For seismic tomography, two accelerometers B\&K 4393 and two 4384, an instrumented hammer and a recording and analysis system PULSE 3560B-020, were used. Seismic tomography was applied to the second column from the left line of columns of the church (Figure 2d). This column was supposed to be the most damaged of the basilica (Figure 3a). The four accelerometers were fixed on the surface, and the hammer hit at the 32 position showed in Figure $3 b$ to obtain enough coverage and to assure sufficient resolution to find all damaged zones. Data were processed by a pulse analysis software, and tomography was computed with ReflexW one (simultaneous iterative reconstruction technique). Seismic tomography has been applied as the main technique to determine the structural configuration and to detect damaged zones of the column.

Seismic monitoring was carried out by a Lennartz seismometer LE-3D/20s recorded by a pulse 3560-B B\&K system. Seismometer was located at each arch, in two positions of the tower and on the floor (Figure 4). Records lasted for 30 min to average more than 30 single spectra by an owner program.

The theoretical coverage for nonrefracted rays travelling from source (hammer) to receivers (accelerometers) is showed in Figure 3b. These straight trajectories can be determined solving Equation (1):

$$
t_{i}=\sum_{j} x_{i j} v_{i}
$$
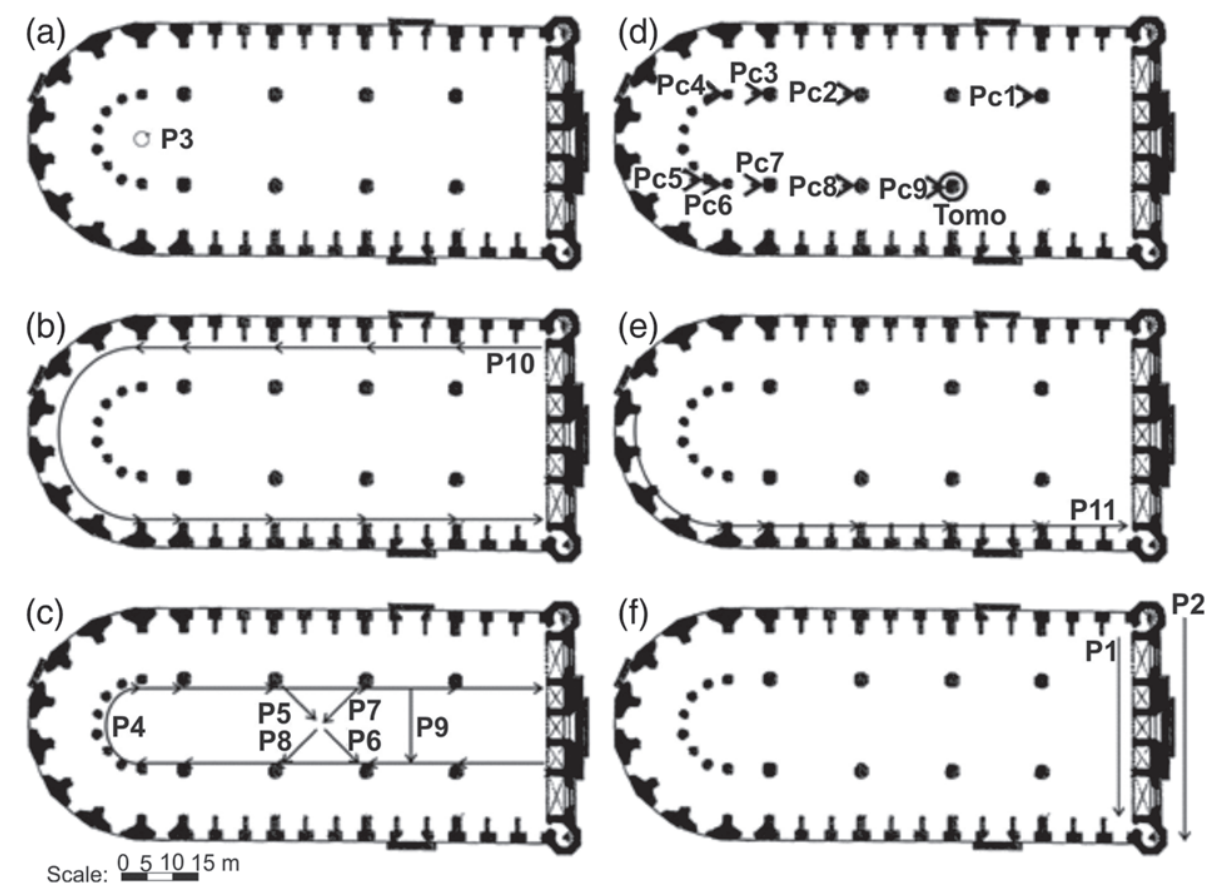

FIGURE 2 Ground-penetrating radar (GPR) survey: Profiles and column tomography. (a) Profile around the cylindrical structure result of the union of the ambulatory arches in the roof of the church. (b) Profile on the roof over the lateral nave. (c) Profiles on the main nave roof. (d) Columns assessed with GPR profiles (Pcn) and column studied with tomography (marked with "Tomo"). (e) GPR profiles on the chapters roofs. (f) Profiles on the floor 

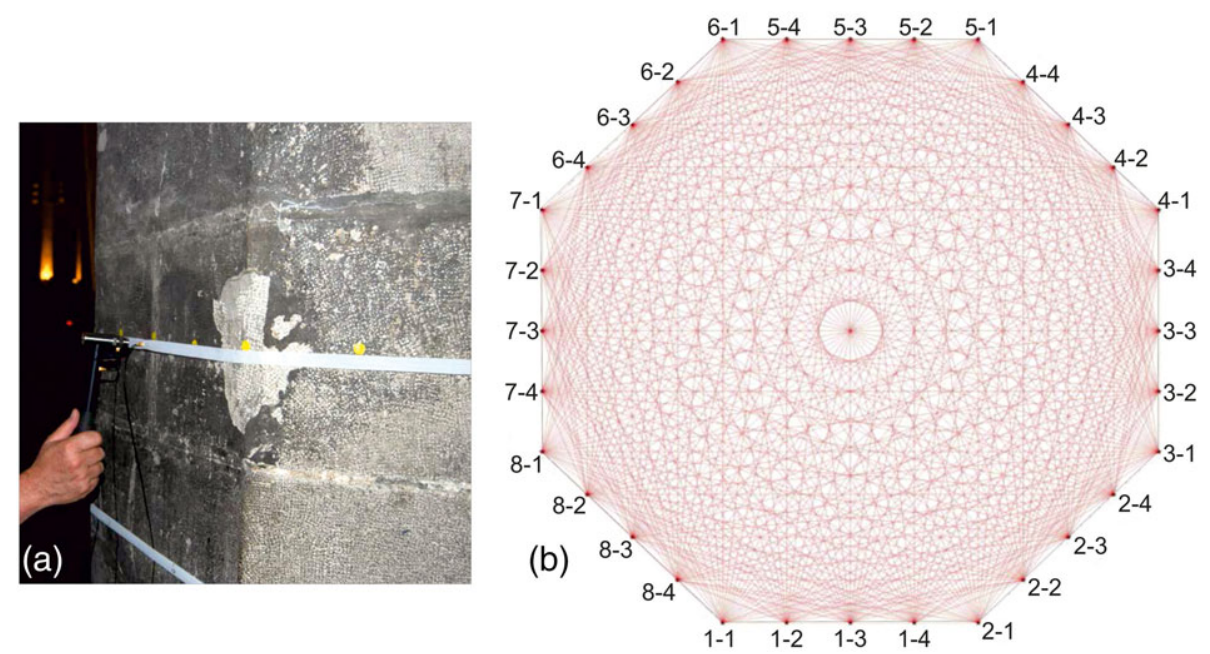

FIGURE 3 (a) Seismic tomography of the column and (b) simulation of the coverage in the case of an ideal homogeneous column
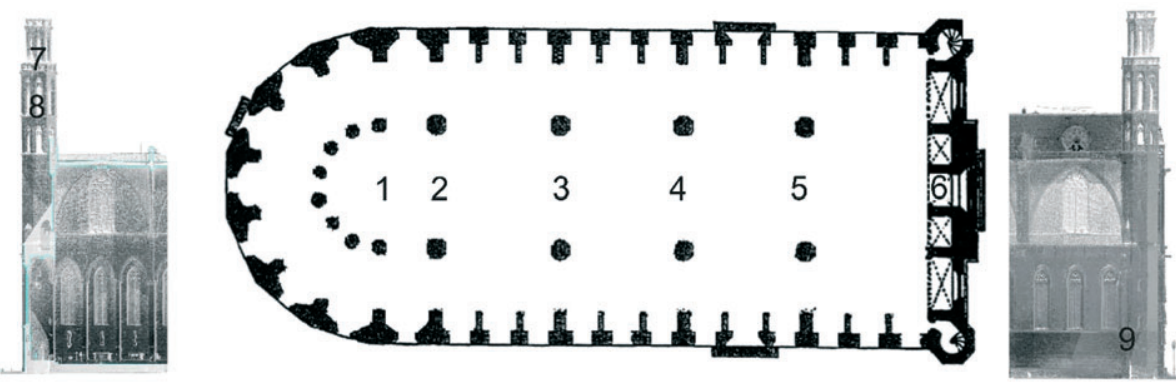

FIGURE 4 Location of the seismic monitoring. The numbers indicate the sensors' position

being $t_{i}$ the travel time between source and receiver measured in the survey, $v_{i}$ the seismic wave velocity, and $x_{i j}$ the wave trajectory.

In order to achieve full coverage of the section of the column, it was divided in cells. Seismic waves are transmitted and refracted at each contact between cells, depending on the properties defined at each one of these elements. Results are obtained as the sum of the values in each one of the cells. In the case of nonhomogeneous media, the properties of the cells change, and the seismic wave is refracted at the interfaces due to changes in the wave velocity associated to adjacent cells. The equations are resolved in an iterative computational process that includes ray curvature as consequence of internal refractions, until convergence of the solution.

\section{3 | RESULTS}

Results are obtained from three main areas: roofs, columns, and ground.

The thickness of the roof depends on the supporting structures: arches, columns, and vaults. Vaults and arches are built with 20-cm-thick ashlars. The smallest thickness of materials is over the keystone between roof and vaults, being about 40 and $50 \mathrm{~cm}$. However, this thickness is variable and can reach from 70 to $100 \mathrm{~cm}{ }^{21}$ This thickness of masonry generates important loads transmitted to the foundations mainly through the columns. The results reveal an ingenious solution to reduce them.

The slender columns transmit most of the loads to the foundations, supporting each one of them about 500 ton. The compressive stress in the base of these structures can reach 3.3 $\mathrm{MPa}^{22}$ Results of the combined analysis exhibit the inner structure of those columns and the possible existence of fissures and damage. 
The church is located on the Barcelona plain, not far from the sea, in an area that was densely populated. The soil is poor, composed by sand and a thin layer of clay. ${ }^{23}$ Results of the ground analysis indicate the existence of some constructions and the location of the foundations.

\section{1 | Results of the roof study}

The images obtained in the GPR assessment of the roof denoted four main important characteristics (Figure 5).

The first one corresponds to the structure of the arches (A in Figure 5). The radargrams show several reflections in the vaults that could correspond to three possible layers with different radii of curvature. The deepest anomaly could be produced by the reflection on the keystone of the vault. The other two anomalies could be associated to the intrados and the extrados. The intrados is the inner curve of the arch, whereas the extrados is the outer curve of the arch. In the radar data, the two anomalies are most likely associated at these two surfaces of the arch, separated by the thickness of the stones. Between the anomalies, the image is clearly uniform. Therefore, materials in this zone are most likely homogeneous, probably composed by ashlars and without irregular filling material.

The second interesting characteristic appeared around the zone over the columns, the widest assessed part. Radargrams obtained in that area are characterized by small hyperbolas (B in Figure 5). These anomalies appear in the area of the thicker roof structure and are produced presumably due to the presence of ceramic pieces. In previous studies of mediaeval churches, this type of material is used as a light infill that contributes to the reduction of loads. Usually, these ceramic pieces are between 0.7 and $1 \mathrm{~m}$ thick and are disposed as a layer embedded in rubble masonry mixed with lime mortar.

The presence of those big hollow ceramic elements is documented in few places of this church (the central vault) and seems to be employed in order to diminish the weight of the building roof. ${ }^{6}$ This constructive peculiarity is consistent with the recorded GPR images, characterized by many small hyperbolas. Moreover, the distribution of the hyperbolas' shape size seems to indicate that those hollow targets could be placed at different depths depending of the thickness of the structure. In addition, the GPR images could indicate that the technique used to reduce loads has been used in different areas of the roof structure and not only in the central vault.

The third characteristic zone in the radargrams corresponds to the junction between arches and columns. The strong reflections could be produced on the capitals of the columns supporting the vaults (C in Figure 5).

Finally, the fourth feature is a flat and homogeneous anomaly related with the load-bearing walls and the arches junction. In this part of the radargrams, no significant hyperbolas are recorded, denoting that the structure is probably built with homogeneous stones (D in Figure 5). Radar data reveal important differences between heterogeneous zones with ceramic vessels between columns and more homogeneous zones near the walls.

As the surface of the roof was uneven in all the sectors, the topography was corrected to determine the volume of material supported by the columns. Figure 6 shows the correction and the surface of the roof. In this section, an undulating shape of the roof corresponds to the different vaults.

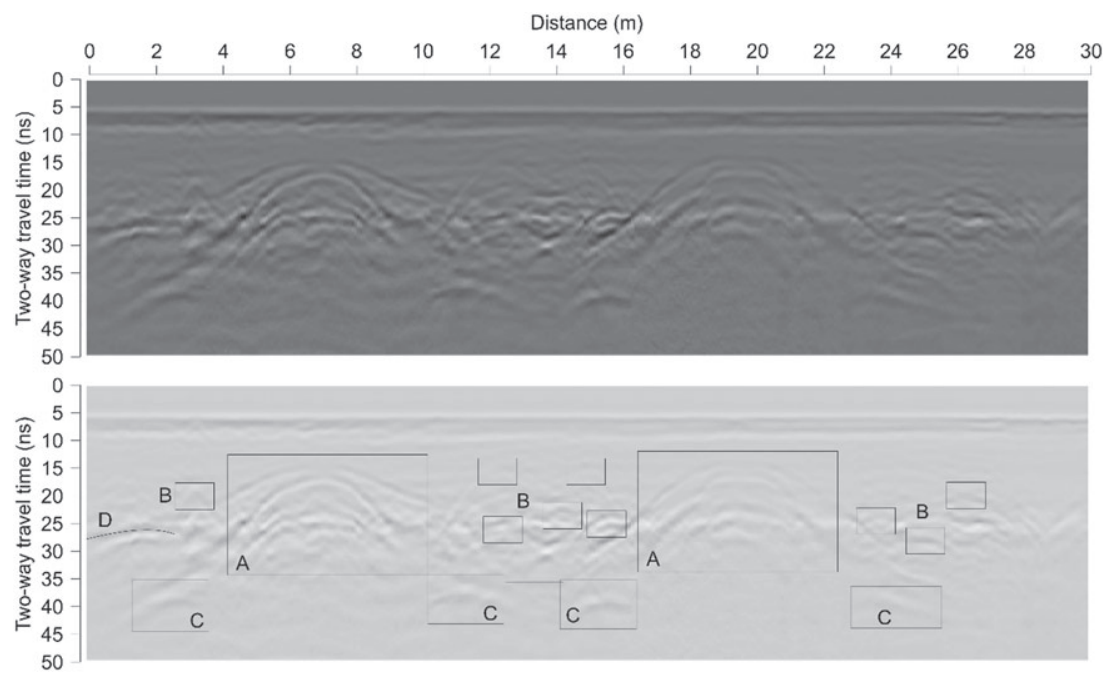

FIGURE 5 Detail of the radar image obtained (only with a bandpass filter applied) in the roof with the $400-\mathrm{MHz}$ centre frequency antenna (part of Profile P4 in Figure 2) and possible interpretation. (a) Reflections on the arch structures. (b) Reflections on heterogeneous filling around the zone over the columns. (c) Reflection on capitals of the columns supporting the vaults. (d) Reflection on homogeneous materials between the vaults and the walls 
FIGURE 6 (a) Radar line P4 over nonflat roof surface. (b) Topographic correction of part of the radargram obtained along P4. Two arches and three columns are detected in this section
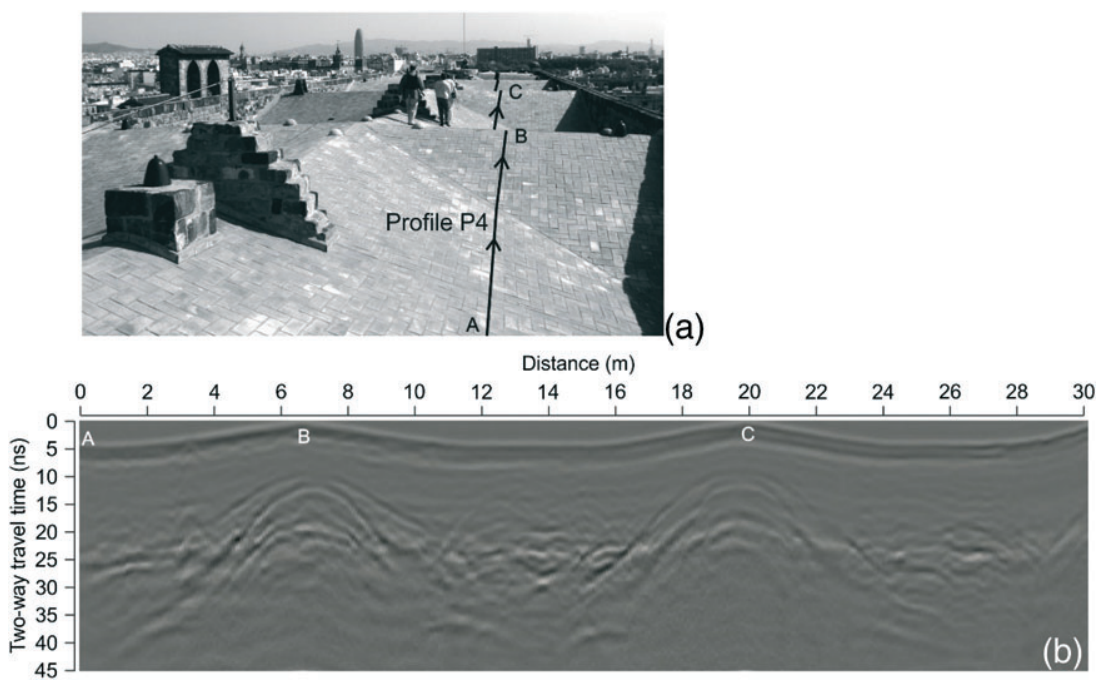

Figure 7 shows a sketch of these possible zones corresponding to the vault structure deduced from the GPR survey, indicating the respective GPR line position. The ceramic hollow vessels between the vault and the upper surface of the roof structure were a possible architectural mediaeval solution to decrease the weight of the covert without reducing the bearing capacity. Therefore, in the structure, a contrast exists between those widest parts, in which the weight was reduced by using hollow targets, and the most homogeneous zones that are composed by solid ashlars and mediaeval concrete (rubble masonry and lime mortar). The thickness of the structure near the load-bearing walls is $150 \mathrm{~cm}$ (Figure 8). The two-way travel time in this zone to the lower anomaly is $20 \mathrm{~cm}$, indicating a wave velocity of about $15 \mathrm{~cm} / \mathrm{ns}$. This velocity is higher than the value assumed or calculated by other authors: about $10 \mathrm{~cm} / \mathrm{ns},{ }^{24}$ between 12 and $13 \mathrm{~cm} / \mathrm{ns},{ }^{25}$ near to $12 \mathrm{~cm} / \mathrm{ns},{ }^{26}$ and from 9.2 to $11.4 \mathrm{~cm} / \mathrm{ns} .{ }^{27}$ The result in the materials could be consequence
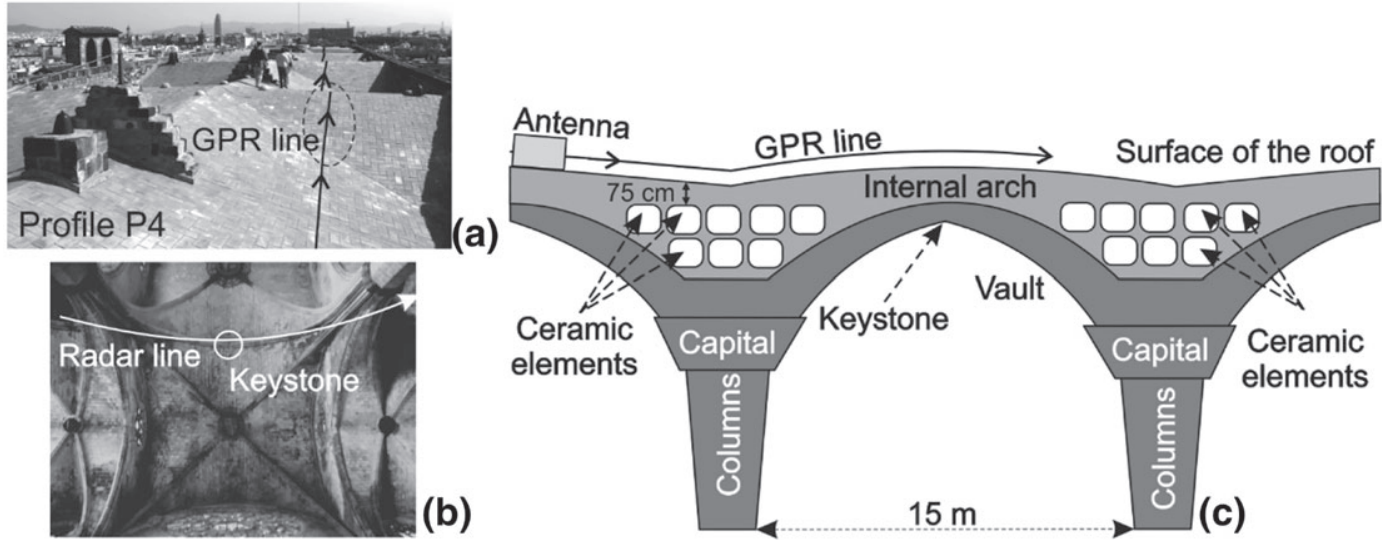

FIGURE 7 (a) Photograph of the roof showing the radar line (Profile P4). (b) Photograph of the vault showing the location of the groundpenetrating radar (GPR) line on the roof and the keystone. (c) A scheme presenting the possible GPR data interpretation of the structure in one vault

FIGURE 8 Detail of the anomalies around zones over columns, corresponding to ceramic elements, most likely amphorae or ceramic bottles. The distance between vaults is $15 \mathrm{~m}$. The thickness of the roof structure in the zone close the load-bearing walls indicates a wave velocity of about $15 \mathrm{~cm} / \mathrm{ns}$ in the most homogeneous mortar

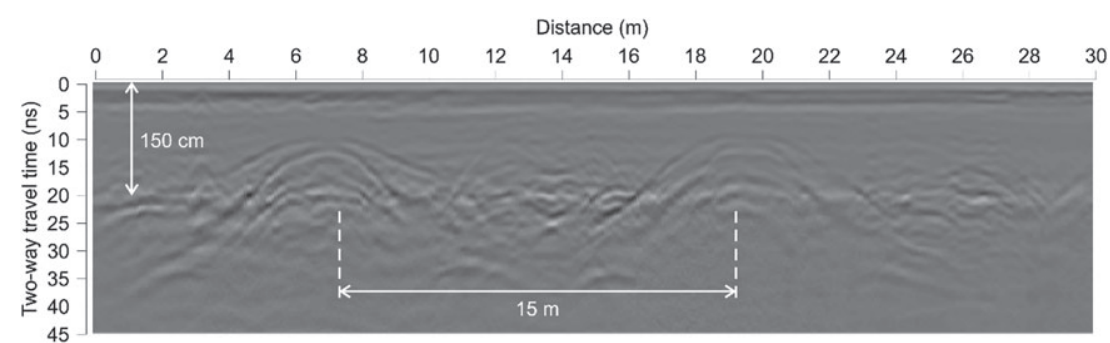


of the heterogeneities in the mediaeval concrete used in the structure. Considering that this velocity corresponds to the mediaeval concrete and ashlars, the depth to the upper part of the vessels could be found at about $75 \mathrm{~cm}$.

Figure 8 shows an image of a section from Profile 4, in which heterogeneous anomalies are associated to hollow elements. The existence in the structure of those hollow targets is due to the use of slender columns to support a wide roof structure. The distribution of the columns inside the church produces a visual impact creating a diaphanous space. Although the inside of the church is a three-nave building, as other gothic churches, the effect is a unique space because of the high distance between columns $(15 \mathrm{~m})$ and a design that equals to the elevations of the three naves. Besides, the rooftop surface is quasiflat, in opposition to European gothic style that was built with very pitched roofs.

Therefore, the wide roof structure must be supported mainly by the tall and separated columns. This kind of structure reduces the weight of the roof structure, and GPR images confirm this solution, determining the zones in which the type of materials allows to reduce the weight. Therefore, it is possible to distinguish between two types of zone. One of them corresponds to a zone composed by ashlars and mediaeval mortar. The other type of the zone contains also hollow elements (ceramic vessels). In radar images, the most homogeneous zones (without ceramic vessels) correspond to the sections in the structure over the arches where the elements between extrados and covert are thinner and to the zones near the load-bearing walls. The zones with a great number of anomalies are clearly distinguished and usually correspond to zones over and around columns. Irregular anomalies in radar data may correspond to scattering in the most heterogeneous elements corresponding to the ceramic vessels embedded in the mediaeval concrete. However, in this particular case, the high amplitude of the reflected waves of some anomalies reveals an important change in the radar wave velocity (as consequence of the change of the electromagnetic properties of the medium), suggesting reflections on voids or hollow targets.

Four profiles (P5 to P8 in Figure 2) crossed the roof of the main nave, each one of them over one column and the corresponding arch. The results (see Figure 9) highlight the existence of the already discussed reflections in the heterogeneous targets around the column junctions. The reflection on a practically continuous target denotes the existence of two levels of stones in the homogeneous zone.

Notwithstanding, the most representative element in this group of radar images is the radargram obtained in Profile 8. This image is highly irregular, and even though it presents similar patterns than the other three radargrams, the heterogeneity appears in the whole image. A possible interpretation points to a more damaged zone, or perhaps a restored zone, using more irregular elements and filling. No actual restorations are documented in this part of the building. It is

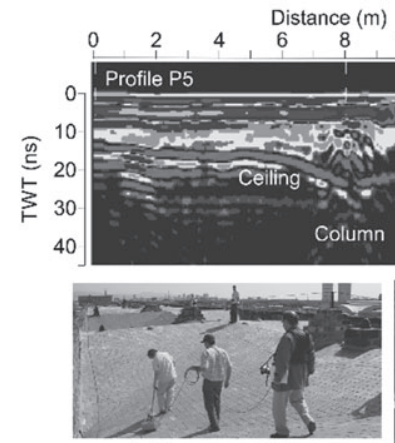

(a)

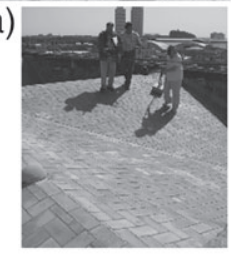

Distance (m)

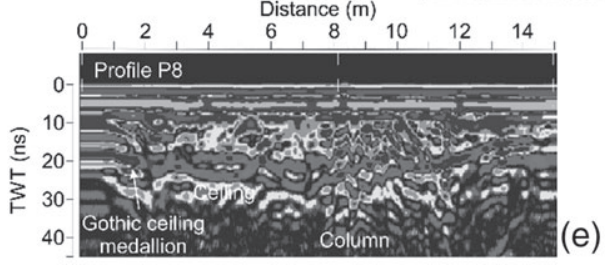

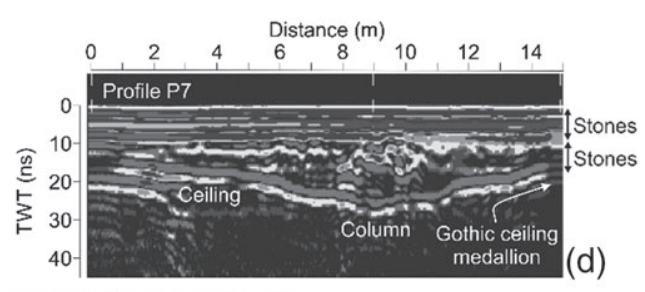

(c)

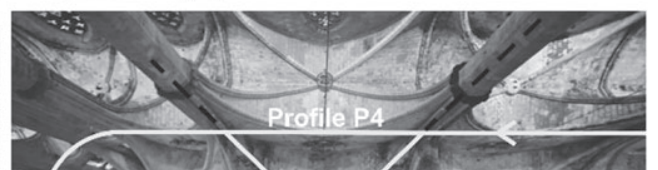

(b)
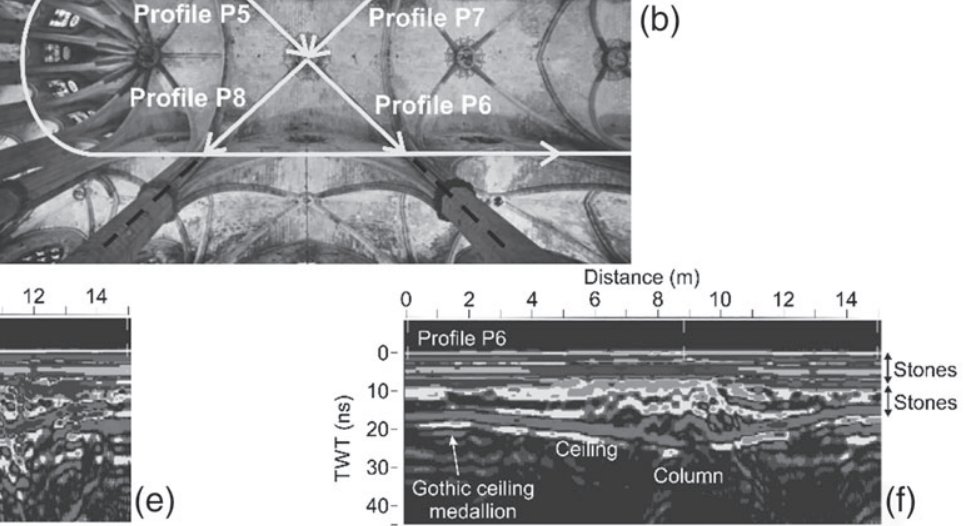

FIGURE 9 Four profiles crossing the roof of the main nave, obtained with a 900-MHz centre frequency antenna. (a) Radar data acquisition. (b) Location of the profiles over the roof. (c-f) Radar data from radar lines P5, P6, P7, and P8, respectively 
a reasonable hypothesis, mainly considering the structural damage after the 1428 earthquake and the fire in 1397 . The differences in this zone are decidedly important to understand the structural behaviour of the building and to design the most appropriate restoration and the preservation planning.

\section{2 | Results of the columns assessment}

The external arrangement of the ashlars in the columns is similar to that observed in other gothic churches with octagonal columns. The GPR images (Figure 10) present analogous characteristics to the columns of other Spanish gothic cathedrals, being similar to those obtained in Mallorca Cathedral. ${ }^{17}$ The columns are composed by rows of regular ashlars. In one row, a shallower reflection appears in both opposite sides of the columns, whereas in the following row, reflection is deeper because the ashlar is rotated $45^{\circ}$ with respect to the first row. The contact between stones is clearly evident. The absence of other important reflections highlights the good state of conservation (Figure 10). Anomalies in radar data correspond mainly to reflections on the ashlars joints. Therefore, it could be considered that the columns are only built with large carved stones separated by thin joints filled with mortar. Despite of the clear images, radar data from isolate profiles are insufficient to determine the inner structure of the columns. Combining the GPR survey with a high resolution seismic assessment could reduce the uncertainty. Therefore, the seismic tomography was applied to determine the inner arrangement of the ashlars. Connections between stones are mortar, characterized by smaller seismic wave velocities than the stones, and might be detected, highlighting the shape of the internal contacts. The damage in the stones could produce lower velocities, indicating areas for deeper analysis.

Seismic tomography provides a more detailed image of the inner arrangement. Results present the seismic velocity distribution (Figure 11). Main velocities range from 2,500 to 3,000 m/s. These velocities correspond to a high-quality limestone. However, results exhibit few zones with very low velocity (about $500 \mathrm{~m} / \mathrm{s}$ ); these zones are located in the ashlars junctions and in the surface of four sides, corresponding to a more irregular surface. The tomography also reveals a deepest zone inside one of the ashlars in which intermediate velocities (between 1,000 and 2,000 m/s) are measured.

The image of the inner column obtained with the tomography facilitates the interpretation of the radar images. The deepest reflections correspond to the row in which the inner squared stone presents the surface parallel to the surface of the column, whereas shallowest reflections correspond to the $45^{\circ}$ rotated stone.

\subsection{Results of the seismic monitoring}

Seismic monitoring allows examining the behaviour of the whole structure. The analysis of the vibration frequencies reveals the dynamic comportment of the building.

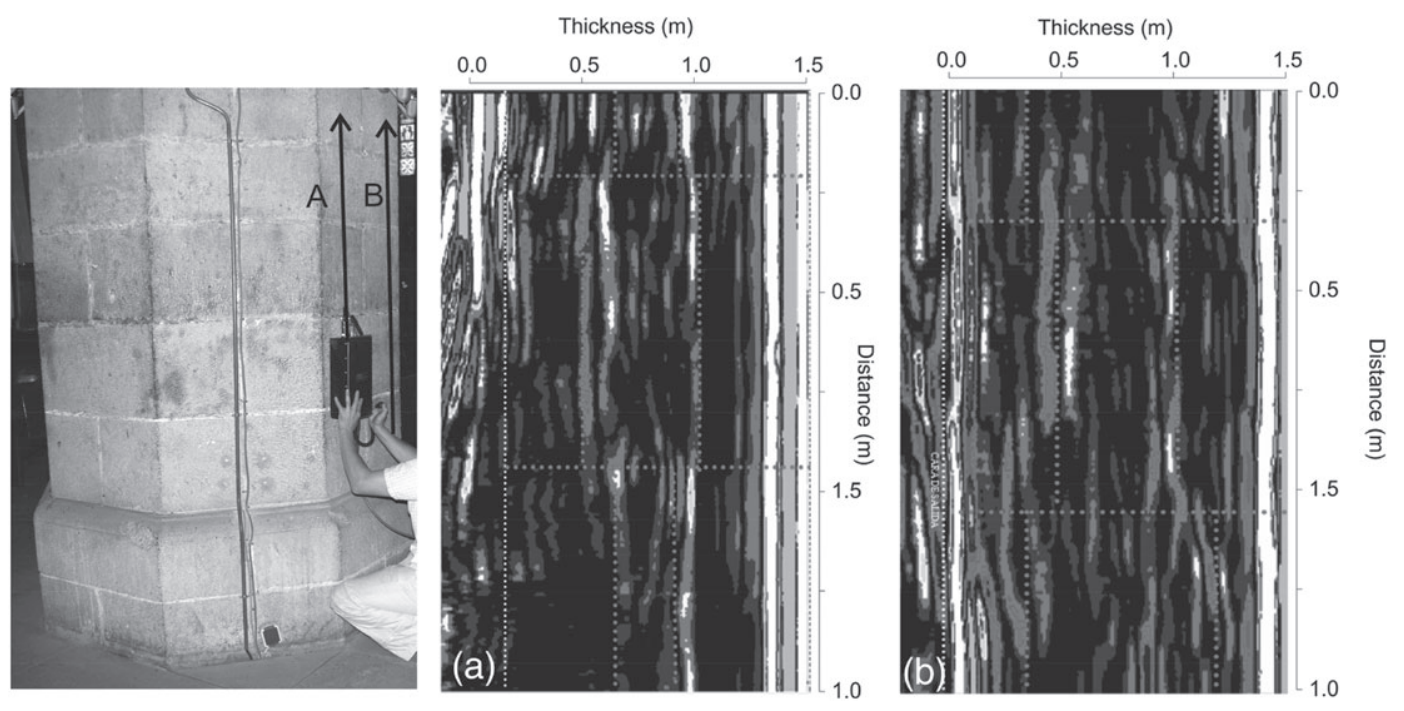

FIGURE 10 Assessing the columns with the 900-MHz centre frequency ground-penetrating radar antenna. The results obtained in two parallel radar lines demonstrate that the columns are composed by ashlars 


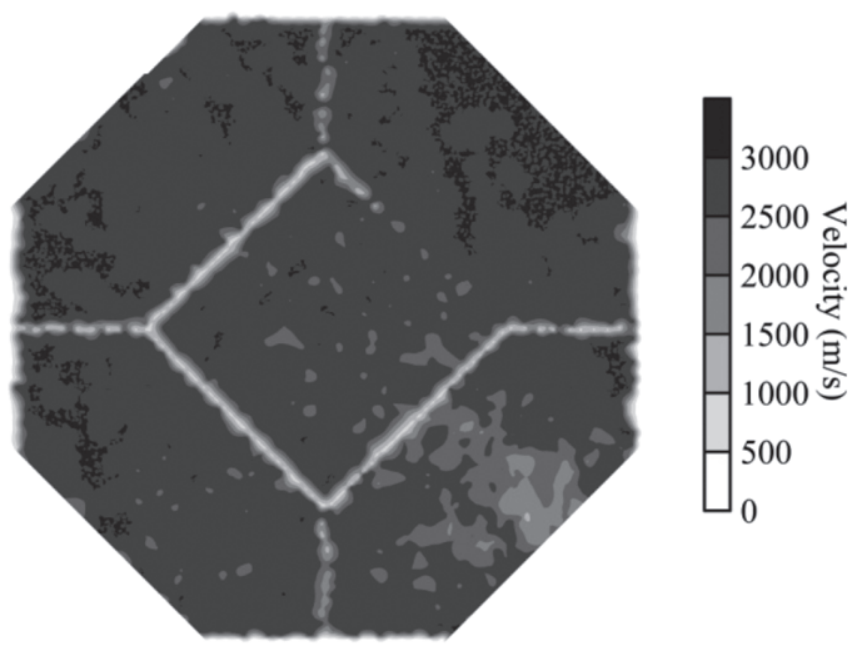

FIGURE 11 Seismic tomography of the column

In Santa Maria del Mar church, the transversal component shows a very ease comportment with only one global frequency of $1.45 \mathrm{~Hz}$. There are also few local frequencies with low energy compared with the global one; the most interesting are the $3.23 \mathrm{~Hz}$ at the façade and $2.70 \mathrm{~Hz}$ at Point 4 (Figures 4 and 12). Figure 12 also reveals that the façade presents a similar behaviour than the nave, comparing results at Points 4 and 6 showed in Figure 4.

Longitudinal comportment is more complex, presenting global frequencies of about 2.05, 2.15, 2.35, 2.75, and $3.77 \mathrm{~Hz}$; a $4.10-\mathrm{Hz}$ local frequency at the ambulatory zone; and a $3.02-\mathrm{Hz}$ frequency value at the façade zone (see Figure 13).

The results of the façade and the tower bell show a very similar pattern compared with the main nave (Figures 13 and 14). However, the spectrum shows a characteristic crack of the peak named breathing effect. ${ }^{28}$ Also, modes 2.05 , 2.35, and $2.75 \mathrm{~Hz}$, in Point 7 (Figures 4, 14, and 15), are transformed from pure longitudinal to bidirectional components probably due to any asymmetry of the towers. Draws of particle motion for each mode ${ }^{5}$ show different comportments.
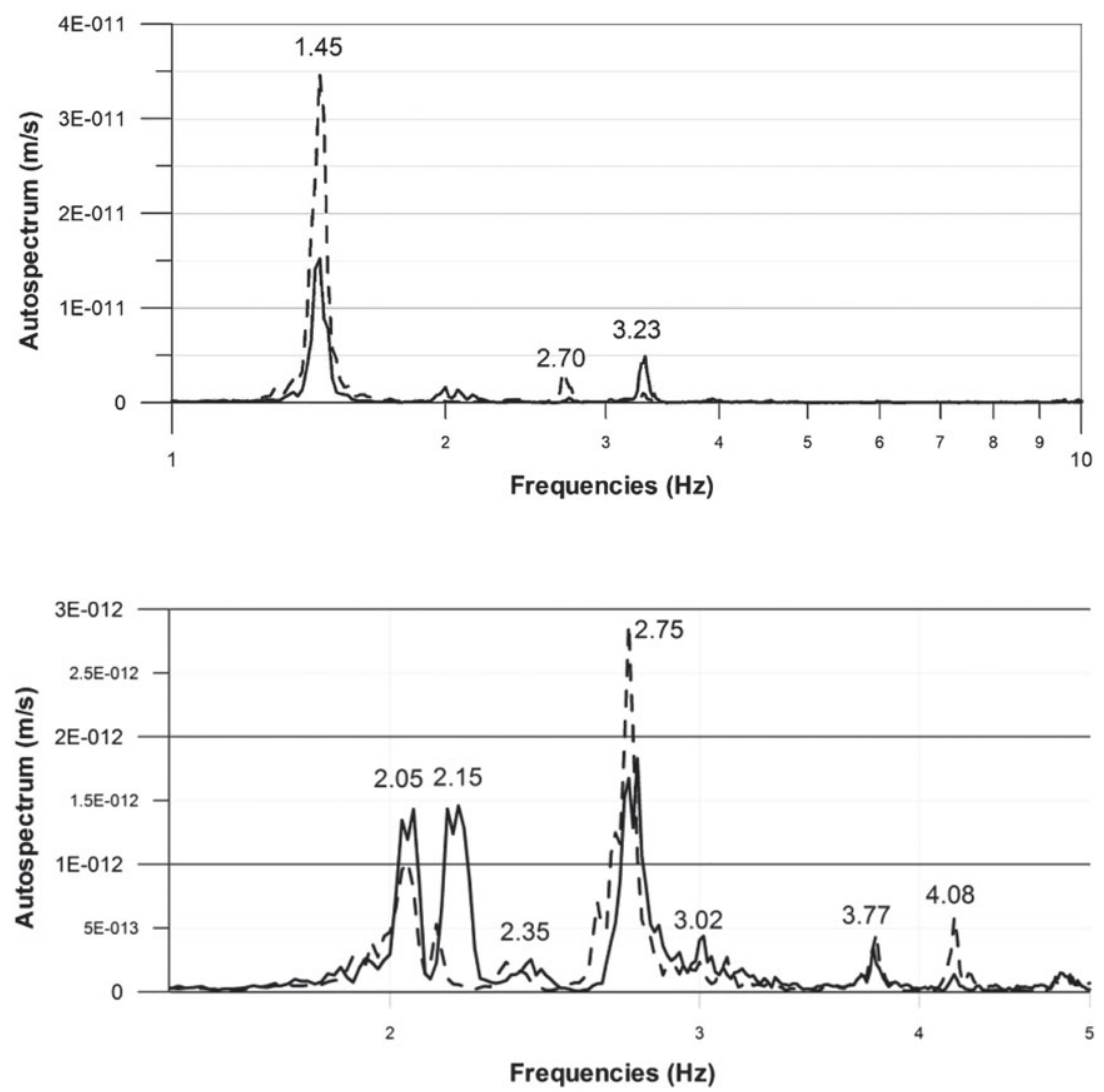

FIGURE 12 Transversal autospectrum at Point 4 (dashed line) and at Point 6 (continuous line)

FIGURE 13 Longitudinal autospectra at Point 1 (dashed line) and Point 6 in the façade (continuous line) 
FIGURE 14 Longitudinal (continuous line) and transversal (dashed line) in Point 7 in the tower
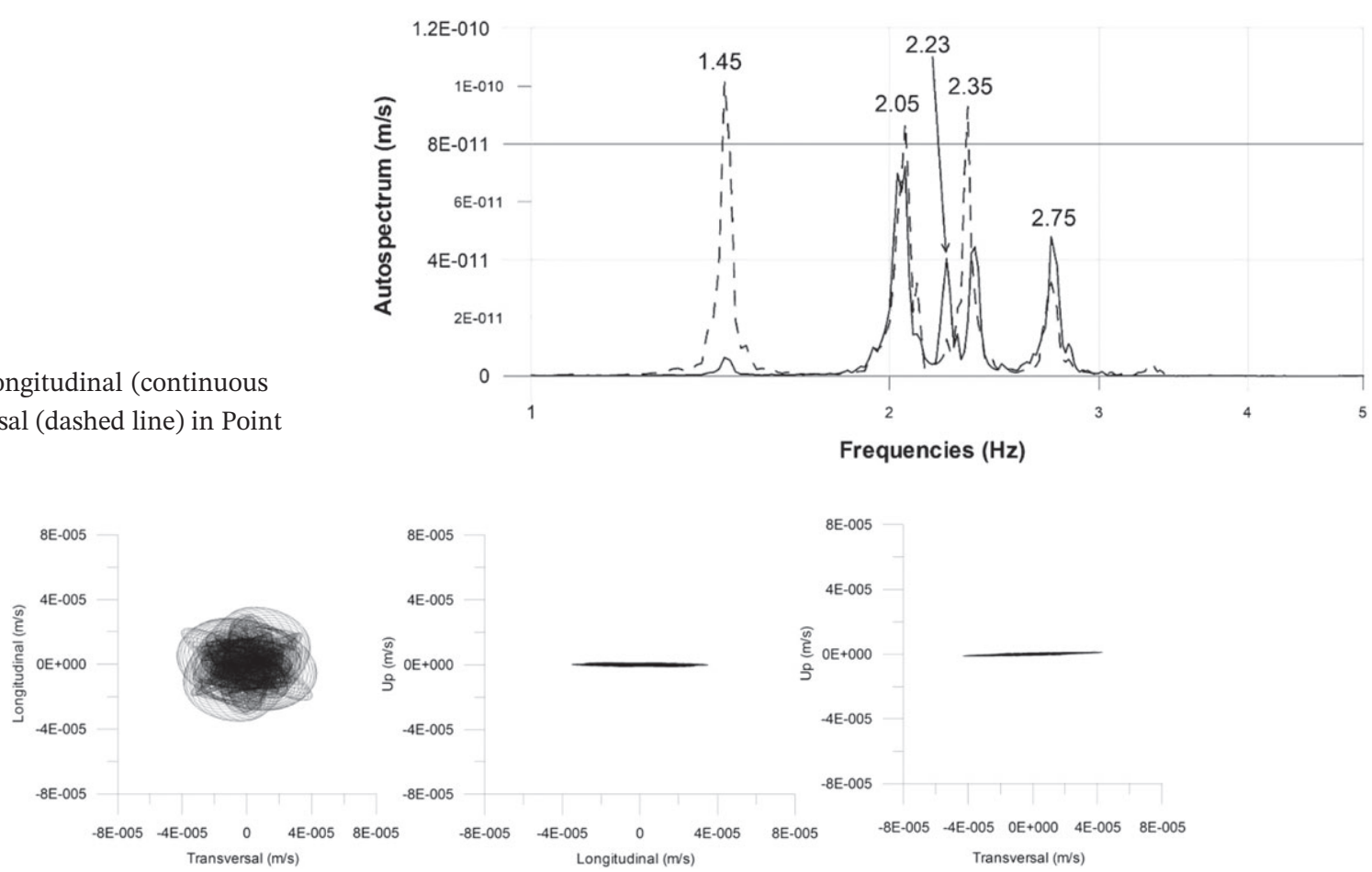

FIGURE 15 Particle motion of the $2.35-\mathrm{Hz}$ mode at Point 7 in the tower

The 2.05- $\mathrm{Hz}$ mode changes from pure longitudinal to $70^{\circ}$ clockwise; the $2.70 \mathrm{~Hz}$ changes to $45^{\circ}$ opposite clockwise, and the 2.13 and $2.75 \mathrm{~Hz}$ change to torsion mode.

Soil sensor detects a very soft soil with energies at frequencies between 0.38 and $0.72 \mathrm{~Hz}$, as it is expected in soft soils. As other great churches, frequencies of the structure are undetected on the floor inside the church few meters long of the columns and walls.

\subsection{Results of the ground study}

The floor and ground were only investigated with GPR. Results related with ground survey inside the main façade show the existence of a slab in the basilica. This slab is most likely not completely homogeneous, given the changes detected in GPR images probably related to historical repairs. In fact, some zones seem to be formed by reinforced concrete.

Under the slab, ground seems to be homogeneous with a possible geological change at about $2.5 \mathrm{~m}$ deep. However, at both sides of the front door, just next to the two columns, important anomalies probably caused by reflections on

FIGURE 16 Radar data inside the church, acquired with the 200-MHz centre frequency antenna showing significant anomalies that could be associated to foundations

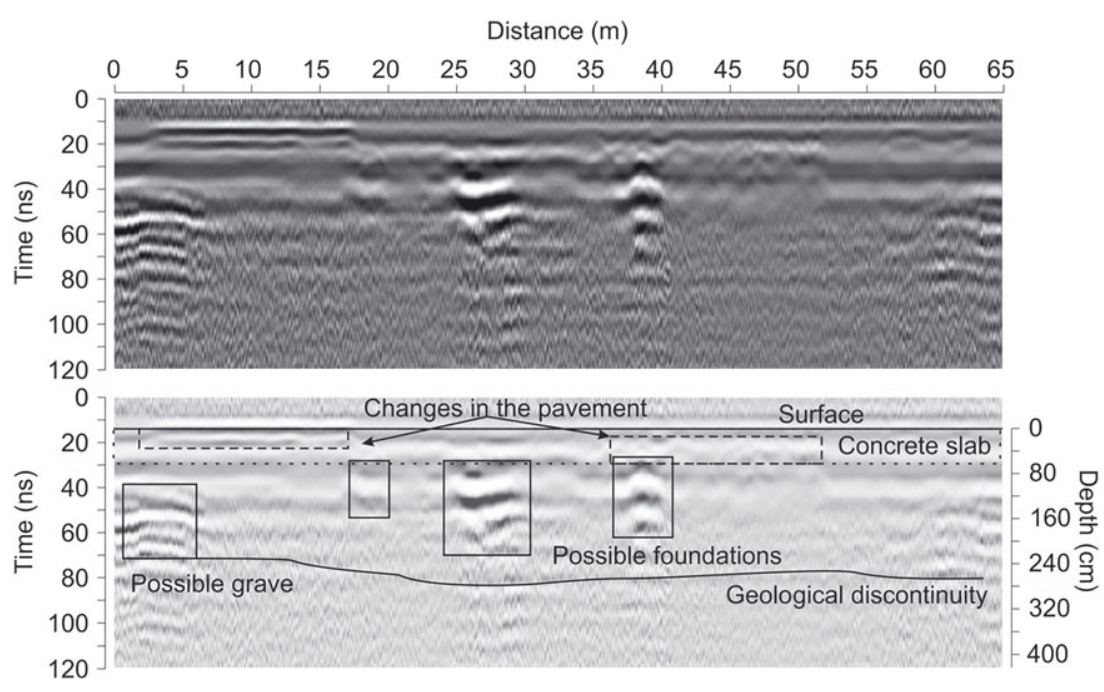




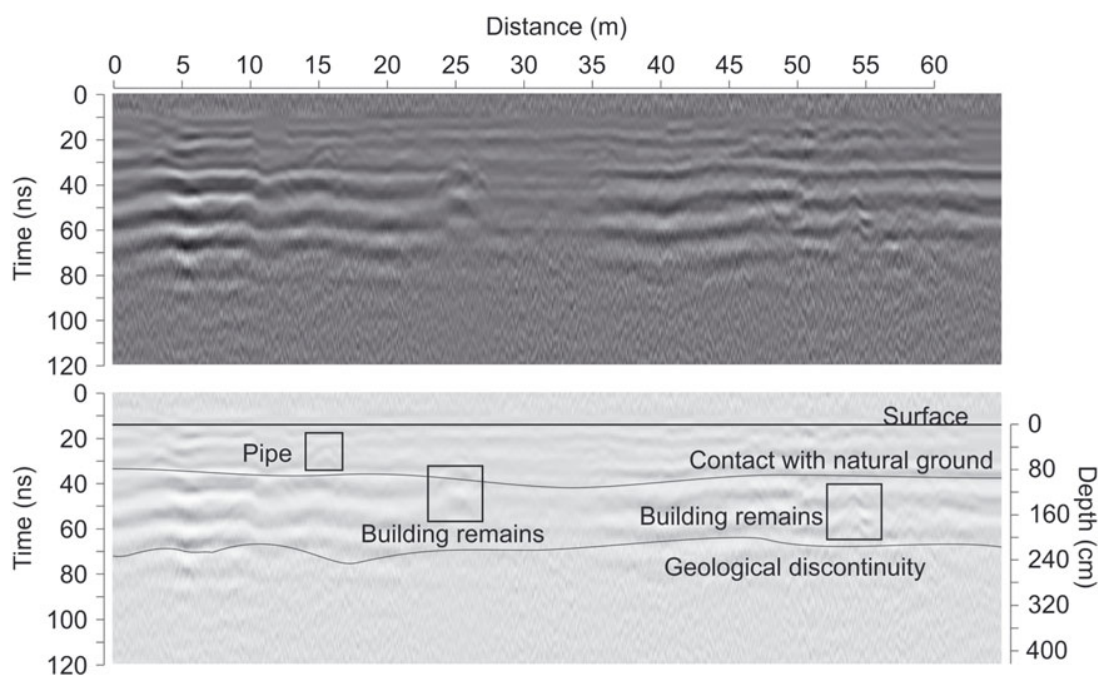

FIGURE 17 Radar data obtained with the $200 \mathrm{MHz}$ centre frequency antenna in front of the main façade, outside the church

church foundation appear. Other anomalies could be associated to graves and buried structures (Figure 16). Outside radar data acquired in front of the basilica also contain some anomalies possibly associated to walls remains of ancient structures (Figure 17).

Therefore, ground results suggest that the church was built a homogeneous layer with few irregular targets, but the existence of cultural heritage remains outside the basilica. Inside the basilica, anomalies could be associated to graves and foundations.

\section{4 | DISCUSSION AND CONCLUSIONS}

The non-destructive assessment of man-made structures requires different approaches to obtain accurate results. This work described the assessment of a cultural heritage building in order to obtain all the possible information to plan the preservation strategy.

In the study of building, two of the required details are the state of conservation of the different structural members and the arrangement of the inner structures. In the particular case of the Santa Maria del Mar church, this information was obtained using three different non-destructive testing techniques: GPR, seismic tomography, and seismic monitoring. These methodologies are inapplicable to each of the elements of the structure, being complementary techniques. In these cases, all the methods are required to obtain structural details. In several cases, two of the methodologies can be used in the assessment of the same element. Therefore, the information is supplementary and can be used to understand better the results and to determine a more accurate interpretation.

The application of the three techniques, in this particular case, allowed the structural characterization and the determination of the respective dynamic comportment. Both are needed in the further evaluation of structural safety when great structures are assessed.

The specific study of the roof demonstrated the existence of peculiar zones in which the constructive materials could be hollow elements. Radar images show heterogeneous areas in which a high number of hyperbolas indicate the existence of layers composed by many targets. These zones are mainly in the roof just over and around the junction of the columns and the ceiling, between the extrados and the rooftop. Results demonstrated the hypothesis of the archaeologists and engineers about the existence of hollow ceramic vessels used to relieve the weight of the structure and the load over the columns. GPR is demonstrated to be an appropriate technique to detect these changes in materials, revealing differences between zones built with regular ashlars and zones built with targets that can be associated to the interesting solution applied in order to decrease the loads as consequence as the roofing weight.

The study of columns with two techniques (GPR and seismic tomography) provided complementary information about the structure. Seismic tomography demonstrates the existence of a squared stone in the centre of the octagonal column being four stones around this central ashlar. GPR images show images compatible with seismic results and indicate that the squared stone is rotated $45^{\circ}$ at each ashlar file. The most time-consuming technique (the tomography) was used only in one column, to diminish the uncertainty of the GPR images. The results helped in the interpretation of the 
radargrams and were also used to interpret the results from other columns, obtained using a GPR common offset (CO) mode, an expedite technique that facilitates the study of all the columns under interest.

Referred to possible damage in columns, from the GPR assessment of nine columns and the seismic tomography in one of them, no evident cracks were detected inside the structures. However, seismic tomography exposes the existence velocities between 500 and 1,500 m/s inside one of the stones, suggesting some damage in the stone. GPR images, without important anomalies, point to damage without cracks. Other ashlars have velocities between 2,500 and 3,000 m/s, which corresponds to high-quality limestone. The most superficial decrease of velocity in four sides of the column can be associated with the most irregular surface and also with the external damage in the stone as consequence of fire effects.

In the assessment of columns, final results from both methods confirm that the seismic tomography could provide a detailed and realistic result. Comparing with CO GPR survey, the fast data acquisition and processing make more appropriate the CO GPR survey for the analysis of large zones and buildings.

GPR survey on the ground has revealed the existence of possible graves and buildings remains inside and outside the main façade. The depth of the geological stratigraphy has been also determined above $4 \mathrm{~m}$. In addition, the method results are also feasible to locate foundations in specific cases.

Seismic monitoring has determined that the main dynamic comportment of the church is only one; the façade, tower, and all naves have a good integrity. Longitudinal comportment is more complex than the transversal one reflecting the higher structural complexity in this direction. Detected breading effect in façade measurement probably points out the possible existence of an important crack near it without other changes in façade dynamic comportment. Tower dynamic bearing demonstrates the perfect junction with all the structure. Asymmetry of the tower probably causes that two longitudinal modes alter the direction of flexion and two more change to torsional modes. Soil dynamic measurement indicates a very soft soil under Santa Maria del Mar façade compatible with the expected soil properties. The church foundation transmits highly attenuated vibration, detected only a few meters from the columns and walls.

\section{ACKNOWLEDGEMENTS}

This research has been partially funded by the project "New Integrated Knowledge based approaches to the protection of cultural heritage from Earthquake-induced Risk-NIKER" funded by the European Commission (Grant Agreement 244123) and by the Spanish Ministry of Economy and Competitiveness (MINECO) of the Spanish Government and European Regional Development Fund (FEDER) of the European Union (UE) through projects referenced as CGL2011-23621 and CGL2015-65913-P (MINECO/FEDER, UE). The research is also a contribution to the EU funded COST Action TU1208, “Civil Engineering Applications of Ground Penetrating Radar."

\section{ORCID}

Vega Perez-Gracia (D) https://orcid.org/0000-0003-3638-3093

\section{REFERENCES}

1. Lourenço PB. Recommendations for restoration of ancient buildings and the survival of a masonry chimney. Constr Build Mater. 2006;20(4):239-251.

2. Himi M, Pérez-Gracia V, Casas A, Caselles O, Clapés J, Rivero L. Non-destructive geophysical characterization of cultural heritage buildings: applications at Spanish cathedrals. First Break. 2016;34(8):93-101.

3. Palet Martínez JM, Orengo Romeu HA, Riera Mora S. Centuriación del territorio y modelación del paisaje en los llanos litorales de Barcino (Barcelona) y Tarraco (Tarragona): una investigación interdisciplinar a través de la integración de datos arqueomorfológicos y paleoambientales. Agri Centuriati. 2011;7:113-133.

4. Sales Carbonell J. Santa María de las Arenas, Santa María del Mar y el anfiteatro romano de Barcelona. Revista d'Arqueologia de Ponent. 2011;21:61-74.

5. Caselles O, Martínez G, Clapés J, Roca P, Pérez-Gracia MV. Application of particle motion technique to structural modal identification of heritage buildings. Int J Archit Herit. 2015;9(3):310-323.

6. Bassegoda i Nonell J. La construcción de las bovedas goticas catalanas. Boletín académico ETSA, N². 1989;11, págs:30-38.

7. Binda L, Saisi A, Tiraboschi C. Investigation procedures for the diagnosis of historic masonries. Construct Build Mater. 2000;14(4):199-233. 
8. Calia A, Lettieri M, Leucci G, Matera L, Persico R, Sileo M. The mosaic of the crypt of St. Nicholas in Bari (Italy): integrated GPR and laboratory diagnostic study. J Archaeol Sci. 2013;40(12):4162-4169.

9. Leucci G, Cataldo R, De Nunzio G. Assessment of fractures in some columns inside the crypt of the Cattedrale di Otranto using integrated geophysical methods. J Archaeol Sci. 2007;34(2):222-232.

10. Pérez-Gracia V, Caselles O, Clapés J, Osorio R, Canas JA, Pujades LG. Radar exploration applied to historical buildings: a case study of the Marques de Llió palace, in Barcelona (Spain). Eng Fail Anal. 2009;16(4):1039-1050.

11. Santos-Assunçao S, Pérez-Gracia MV, Caselles O, Clapes J, Salinas V. Assessment of complex masonry structures with GPR compared to other non-destructive testing studies. Remote Sens (Basel). 2014;6(9):8220-8237.

12. Martinho E, Dionísio A. Main geophysical techniques used for non-destructive evaluation in cultural built heritage: a review. $J$ Geophys Eng. 2014;11(5):053001.

13. Masini N, Persico R, Rizzo E, et al. Integrated techniques for analysis and monitoring of historical monuments: the case of San Giovanni al Sepolcro in Brindisi, southern Italy. Near Surface Geophys. 2010;8(5):423-432.

14. Pérez-Gracia V, Solla M. Inspection procedures for effective GPR surveying of buildings. In: Civil Engineering Applications of Ground Penetrating Radar. Switzerland: Springer International Publishing; 2015:97-123.

15. Cataldo R, De Donno A, De Nunzio G, Leucci G, Nuzzo L, Siviero S. Integrated methods for analysis of deterioration of cultural heritage: the Crypt of "Cattedrale di Otranto". J Cult Herit. 2005;6(1):29-38.

16. Masini N, Soldovieri F. Integrated non-invasive sensing techniques and geophysical methods for the study and conservation of architectural, archaeological and artistic heritage. J Geophys Eng. 2011;8(3).

17. Pérez-Gracia V, Caselles JO, Clapés J, Martinez G, Osorio R. Non-destructive analysis in cultural heritage buildings: evaluating the Mallorca cathedral supporting structures. NDT\&E Int. 2013;59:40-47.

18. Perez Gracia V, Canas JA, Pujades LG, et al. GPR survey to confirm the location of ancient structures under the Valencian Cathedral (Spain). J Appl Geophys. 2000;43(2-4):167-174.

19. Perez-Gracia V, Caselles JO, Clapes J, Osorio R, Martinez G, Canas JA. Integrated near-surface geophysical survey of the Cathedral of Mallorca. J Archaeol Sci. 2009;36(7):1289-1299.

20. Solla M, Lorenzo H, Rial FI, Novo A. GPR evaluation of the Roman masonry arch bridge of Lugo (Spain). NDT \& E Int. 2011;44(1):8-12.

21. Roca P. Study of gothic churches: inspection, monitoring and structural analysis. Tecnología de la Rehabilitación y Gestión del Patrimonio Construido (REHABEND 2009). 2009;1-19.

22. Murcia-Delso J, Das AK, Roca M, Cervera M. Seismic safety analysis of historical masonry structures using a damage constitutive model. In: Thematic Conference on Computational Methods in Structural Dynamics and Earthquake Engineering; 2009.

23. Murcia, J. (2008). Seismic analysis of Santa Maria del Mar church in Barcelona (Doctoral dissertation, Master thesis, Technical University of Catalunya, Spain).

24. Van Hemelrijck D, Vanlanduit S, Anastasopoulos AA, Philippidis TP. Emerging Technologies in Non-Destructive Testing VI: Proceedings of the 6th International Conference on Emerging Technologies in Non-Destructive Testing. Brussels, Belgium, 27-29 May 2015: CRC Press; 2015.

25. Hamrouche R, Klysz G, Balayssac JP, et al. Numerical modeling of ground-penetrating radar (GPR) for the investigation of jointing defects in brick masonry structures. Non-Destr Test Civ Eng NDTCE. 2009;9.

26. Pérez-Gracia V, García F, Pujades LG, Drigo RG, Di Capua D. GPR survey to study the restoration of a Roman monument. J Cult Herit. 2008;9(1):89-96.

27. Leucci G, Negri S, Carrozzo MT. Ground penetrating radar (GPR): an application for evaluating the state of maintenance of the building coating. Ann Geophys. 2003;46(3).

28. Elyamani A, Caselles O, Roca P, Clapes J. Dynamic investigation of a large historical cathedral. Struct Control Health Monit. 2016;24(3): e1885. https://doi.org/10.1002/stc.1885

How to cite this article: Perez-Gracia V, Santos-Assunçao S, Caselles O, Clapes J, Sossa V. Combining ground penetrating radar and seismic surveys in the assessment of cultural heritage buildings: The study of roofs, columns, and ground of the gothic church Santa Maria del Mar, in Barcelona (Spain). Struct Control Health Monit. 2019;26:e2327. https://doi.org/10.1002/stc.2327 